\section{El radioinmunoensayo}

\author{
Enrique Ardila, MD.
}

Médico internista endocrinólogo

Miembro de número Asociación Colombiana de Endocrinología, Diabetes y Metabolismo

Editor Revista ACE

$\mathrm{L}$ a creación del radioinmunoanálisis o radioinmunoensayo supuso para la medicina y en especial para la endocrinología un extraordinario avance. Significó un fuerte empuje a la investigación de la diabetes, así como al diagnóstico y tratamiento de problemas hormonales relacionados con el crecimiento, la función tiroidea y la fertilidad. Se utilizó también para prevenir el retraso mental en los recién nacidos con hipotiroidismo. Todo ello se debe en buena medida a la labor desarrollada por Rosalyn Sussman Yalow y Salomon Berson, en los Estados Unidos, y al doctor Ekins, en Inglaterra ${ }^{(1)}$.

\section{Fundamentos del radioinmunoensayo (RIA)}

El radioinmunoensayo es un tipo de inmunoensayo o método radioinmunométrico que se basa en la formación específica de los complejos antígeno-anticuerpo, lo que lo dota de una gran especificidad, unida a la gran sensibilidad de los métodos radiológicos.

Este método se basa en la competencia existente entre el anticuerpo no marcado y una cantidad conocida del antígeno marcado para formar los complejos AgAc o Ag*Ac. Con estos tres componentes $\left(\mathrm{Ag}, \mathrm{Ag}^{*}\right.$ y $\mathrm{Ac}$ ) puede realizarse el ensayo en el que, manteniendo constante la cantidad de $\mathrm{Ag}^{*}$ y Ac, se observará que a mayor cantidad de $\mathrm{Ag}$ menos $\mathrm{Ag}^{*}$ queda unido a la cantidad fija de Ac (y, por lo tanto, se medirá menos radiactividad), lo que permitirá relacionar la radioactividad con la concentración de $\mathrm{Ag}^{(2)}$.

La creación de esta metodología data de los años 50 del siglo pasado en la Universidad de Nueva York, y se debe a dos investigadores americanos: Rosalyn Sussman Yalow y Salomon Berson, la primera doctora en física y el segundo internista, mediante la dosificación de la insulina; pero también en la misma época otro investigador en Inglaterra, el doctor Ekins, creó una metodología muy similar para la tiroxina, claro que nunca tuvo el impacto y reconocimiento que tuvieron los doctores Yalow y Berson.

\section{Los investigadores}

\section{Rosalyn Sussman Yalow (1921-2011)}

Hija de emigrantes judíos, nació el 19 de julio 1921 en el Bronx, Sur, de Nueva York y era la menor de una familia de clase trabajadora. Su padre se ganó la vida como conductor de tran- vías y más tarde en pequeños negocios. Desde pequeña, la doctora Yalow demostró ser una niña brillante, aficionada a la lectura, las matemáticas y la química. La lectura de la biografía de Marie Curie y la asistencia a una conferencia sobre fusión nuclear contribuyeron a su decisión de licenciarse en física. Por esa época, finales de los años 30, la física nuclear estaba en pleno desarrollo ${ }^{(3)}$.

En 1939 asistió a un semina-

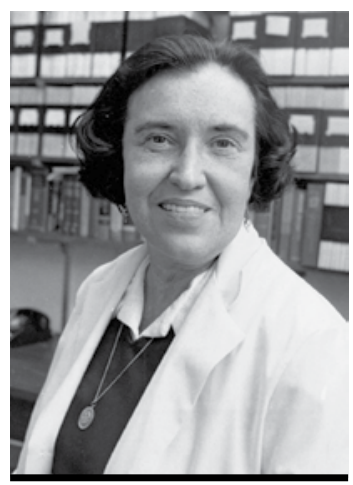

rio de Enrico Fermi, físico italiano, conocido por haber desarrollado el primer reactor nuclear y por sus contribuciones a la teoría cuántica y la física nuclear y de partículas, lo que le causó un gran impacto. Más tarde, Rosalyn se sintió influida por el químico húngaro George de Hesevey, quien en 1923 estudió la radioactividad absorbida por los vegetales y la posibilidad de medir reacciones químicas.

Creció en una época en que se partía de la idea de que las mujeres eran intelectualmente inferiores a los hombres $y$, por tanto, tenían un acceso restringido a la ciencia. Consiguió un puesto de profesora ayudante en la Escuela de ingenieros de la Universidad de Illinois y descubrió que era la única mujer entre 400 alumnos y la primera desde 1917. Se doctoró en física nuclear en $1945^{(4)}$.

Hay que tener en cuenta que, según algunos autores, había sido rechazada por la Universidad de Pardue, Indiana, por tres motivos: por provenir de Nueva York, por ser judía y por ser mujer. En la Universidad de Illinois conoció a Aaron Yalow quien, como ella, comenzaba los estudios de posgrado. Era hijo del rabino de un suburbio rural en la parte norte de Nueva York. En 1943 se convirtió en su marido.

Regresaron a Nueva York en septiembre de 1945, establecieron su casa en Manhattan y después en una pequeña casa en Bronx. Tuvieron dos hijos, Benjamín y Elanna. En 1950 la doctora Yalow abandonó la enseñanza y decidió dedicarse de tiempo completo a la investigación. Necesitaba de alguien con gran experiencia clínica, además jamás había dictado un curso de biología. Allí conoció a Salomon Berson que se había comprometido a ocupar un puesto en el Hospital de Veteranos de Bedford, Massachusetts, fue tan grande el impacto que tuvieron el uno del otro, que el doctor Berson renunció a su puesto y se unió al equipo de Yalow en el Hospital de Veteranos de Bronx, en donde fue jefe de la Unidad de Radioisótopos. Comenzó una colaboración que se prolongó durante 22 años hasta que éste falleció el 11 de abril de $1972^{(5)}$. 


\section{Salomón Berson (1918-1972)}

Nació en Nueva York en 1918, estudió en la Escuela de Medicina de Nueva York, donde obtuvo el título de médico en 1945, luego trabajó dos años en la Armada de los Estados Unidos, más tarde realizó residencia en Medicina Interna en el Bronx VF Hospital. En 1950 ingresó al departamento de radioisótopos de ese hospital, en donde encontró a la doctora Ya-

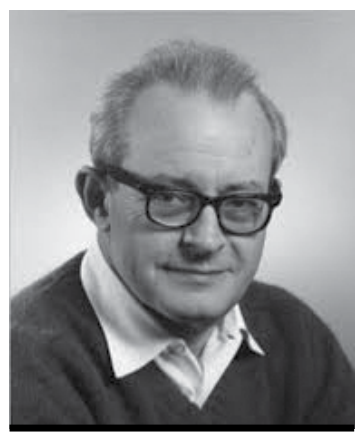
low, con quien realizaría doble actividad, una sentimental, que los llevó a contraer matrimonio tres años más tarde, y otra investigativa que culminó con el desarrollo del radioinmunoensayo ${ }^{(6)}$.

El primer artículo escrito por Berson fue rechazado por la revista Science en febrero de 1956 y fue publicado más tarde por el Journal of Clinical Investigation. En esa época se pensaba que cuerpos tan pequeños como la insulina no podían generar anticuerpos. Esto hizo que su primer trabajo con la doctora Yallow fuera rechazado y solamente fuera admitido cuando se eliminó la palabra "anticuerpo"(7).

Salomon Berson además fue maestro de ajedrez, experto jugador de bridge, estudió violín, fue crítico de arte y excelente matemático, por lo que lo llamaban el Caballero del Renacimiento. Murió a los 54 años en forma repentina durante un congreso en Atlantic City en 1972, sin alcanzar a recibir la máxima condecoración de la comunidad científica internacional, el Premio Nobel de Medicina en 1977.

\section{Estudios experimentales}

Con el doctor Berson, la doctora Yalow comenzó a estudiar la aplicación de los radioisótopos en la determinación del volumen de la sangre, el diagnóstico de las enfermedades de la tiroides, así como la cinética del metabolismo del yodo. También aplicó esta técnica a las hormonas, que circulan en cantidades ínfimas y para cuya detección es necesario utilizar isótopos radioactivos para aplicarle una marca a la molécula y generar anticuerpos contra la misma. De esta forma se produce una competencia entre la molécula marcada y la circulante por una cantidad limitada de anticuerpo generada por la molécula objeto de estudio. El desplazamiento de la forma marcada es proporcional a la cantidad de sustancia que está circulando. Posteriormente, si se agrega un segundo anticuerpo desarrollado en otra especie animal, permite la separación de las dos moléculas para realizar la medición ${ }^{(8)}$.

El origen de la investigación era comprobar si la causa de la diabetes era la formación de una enzima que destruía la insulina circulante. Los diabéticos se inyectaban insulina animal que generaba anticuerpos que acababan por inactivarla. Los niveles detectados en los diabéticos por RIA eran más altos que en los sujetos sanos, lo que posteriormente permitió en- tender la fisiopatología de la diabetes tipo 2 y el nacimiento, más tarde, del concepto de resistencia a la insulina.

Esta metodología dio comienzo ya en la década de los años sesenta a la era del radioinmunoensayo (RIA) que lo convirtió en un productivo campo de investigación científica y de aplicación en el conocimiento de diferentes cuadros clínicos que han ido más allá de la endocrinología, permitiendo entender diferentes procesos fisiopatológicos, además de que ayudó a la creación de otras metodologías de laboratorio más sensibles y específicas, además de más sencillas (como ELISA y la quimoluminiscencia), pero siempre basadas en los conceptos generados por el RIA.

En 1977 se le otorgó a Rosalyn S. Yalow el premio Nobel de Medicina, que compartió con Roger Guillemin y Andrew V. Schally, por sus investigaciones relacionadas con las hormonas peptídicas y por sus avances tanto en el diagnóstico como en el tratamiento de las enfermedades del tiroides, la diabetes, anomalías del crecimiento, hipertensión y esterilidad. Aunque no se había puesto en duda su autoría en los trabajos que firmó con Berson, cuando este murió parece que tuvo que demostrar a la comunidad científica que él no era el único cerebro y que ella no era una mera colaboradora (se alcanzó a decir que "Berson era el cerebro y Yalow las manos")(9).

Rosalyn S. Yalow falleció en Nueva York el 30 de mayo del 2011 a la edad de 90 años.

\section{Panorama en Colombia}

Esta metodología de laboratorio se comenzó a implementar en nuestro país en la década de los años sesenta, en la Universidad del Valle, gracias a los trabajos de la doctora Matilde de Bernal, en la Universidad Nacional por el doctor Bernardo ReyesLeal y en la Universidad Militar por el doctor Carlos Tafurt ${ }^{(10,11)}$; además son de tener en cuenta los trabajos realizados por el doctor Éfraim Otero en el Instituto Nacional de Cancerología ${ }^{(12)}$.

\section{Referencias}

1. Odell WD., Wilber JF., Paul WE. Radioimmunoassay of thyrotropin in human serum. J. Clin. Endocrinol. Metab. 1965. 25(9): 11-79-1188.

2. Berson SA., Yalow RS, Azulay A., Schreiber S., Bernard R., Roswit B. The biological decay curve of P32 tagged erythrocytes; application to the study of acute changes in blood volume. J. Clin. Invest. 1952. Jun, 31 (6): 581-591.

3. Friedman A. Remembrance: The Berson and Yalow Saga. J. Clin Endocrinol. Metab.2002. 87 (5): 1925-1928.

4. Un camp de margarides. L'ultra cara de www.biologiageologia.com Rosalyn Yalow desarrolló el radioinmunoensayo para analizar moléculas biológicas. Dissabte, 21 de febrero 2009.

5. Rosalyn Yalow- Biographical (internet) y Korin M. Dra. Rosalyn Yallow (nternet)

6. Gamez E. Historia del radioinmunoensayo. Dr.Salomon Berson (1918-1972). Un caballero del renacimiento. 12 feb. 2010. Sociedad Mexicana de Nutrición y Endocrinología. Clickderecho.com.mx.

7. Berson SA., Yalow RS., Bauman A., Rothschild MA., Newely K. Insulin I131 metabolism in humans subjects: demonstration of insulin binding globulin in the circulation of insulin treated subjects. J.Clin.Invest. 1956. Feb. 35 (2):170-190.

8. Berson SA-, Yalow RS. General principles of radioimmunossay 1968. Clin. Chim. Acta. 2006 Jul. 23. 369(2): 125-143.

9. Straus E. Rosalyn Yalow Nobel laureate: her life and work in medicine. New York Basic Books, 1990.

10. Reyes-Leal B. Diabetes mellitus. Bases experimentales de nuevos conceptos etiológicos. Rev.Soc.Endocrinol. 1966. 4(1): 85-95.

11. Tafurt CA., Estrada de R., Garcia J. Niveles de proteína transportadora de hormonas sexuales (PTHS) y de testosterona en el embarazo en relación al sexo fetal Rev.Soc.Colomb.Endocrinol. 1978. 11: 59-64.

12. Otero-Ruiz. E. Autoinmunidad tiroidea: Recuerdos personales (1957-1962) Medicina (Bogotá) Sept.2011. 33(3): 179-185. 